\title{
Depressive Symptoms in Schizophrenic Patients
}

\author{
A. Gozdzik-Zelazny ${ }^{1}$, L. Borecki ${ }^{1}$, M. Pokorski1,2 \\ ${ }^{1}$ Institute of Psychology, Opole University, Opole, Poland; ${ }^{2}$ Medical Research Center, Polish Academy of Sciences, Warsaw, Poland
}

\begin{abstract}
Distinction between true negative and depressive symptoms in schizophrenia is difficult. In the present study we seek to establish the psychological profile of depression-prone schizophrenic patients. We addressed the issue by comparing the expression of psychological indices, such as the feelings of being in control of events, anxiety, mood, and the style of coping with stress in depressive and non-depressive schizophrenics. We also analyzed the strength of the association of these indices with the presence of depressive symptoms. A total of 49 patients (18 women and 31 men, aged 23-59) were enrolled into the study, consisting of a self-reported psychometric survey. We found that the prevalence of clinically significant depression in schizophrenic patients was 61\%. The factors which contributed to the intensification of depressive symptoms were the external locus of control, anxiety, gloomy mood, and the emotion-oriented coping with stress. We conclude that psychological testing may discern those schizophrenic patients who would be at risk of depression development and may help separate the blurred boundaries between depressive and negative symptoms of schizophrenia.
\end{abstract}

Key words: Anxiety, depression, locus of control, schizophrenia, stress

\section{INTRODUCTION}

Negative symptoms in schizophrenia, which appear to reflect a diminution of normal functions, such as apathy, lack of emotion, or poor social functioning, are similar to those in depression [1]. It is commonly held that depressive symptoms are frequent among schizophrenics, with the broad frequency oscillating between $10-75 \%$ [2-4]. Such symptoms often are related to suicidal thoughts in schizophrenia $[5,6]$. So many as 2$13 \%$ of schizophrenics eventually commit suicide and most of them experience depressive symptoms at some point of life, especially the feelings of helplessness and loss $[7,8]$. Depressive symptoms often contribute to schizophrenia exacerbation [9] and, when present at initial admission to hospital, may augur a quick relapse [10]; all of which makes the recognition and treatment of depression of paramount importance in schizophrenia. The large scatter in the frequency of depression in schizophrenics above outlined seems to have reflected the ambiguity of distinguishing between the negative symptoms of schizophrenia and those of depression. Siris \& Bench [4] ar- gued that the ascribing symptoms to one or the other condition should be based on the nature of affective disorder present, with sadness predominating in depression and apathy in schizophrenia. Apart from the subtle difference between these two affective states, this criterion is not universally accepted.

From the clinical standpoint it seems worthwhile to establish a psychological profile of the schizophrenic who might be vulnerable to depression during the course of his disease. In the present study, therefore, we seek to determine the association of some psychological indices, such as the locus of control, anxiety, mood, and the strategy of coping with stress, all of which underlie changes in affective state, with the presence of depression in schizophrenic patients. We addressed the issue by comparing the expression of these indices, as assessed by psychometric tools, in depressive and non-depressive schizophrenics. Overall, the study demonstrates that the assessment of the psychological indices could help recognize the appearance of depression in schizophrenia.

\section{Material AND Methods}

The study was carried out in accord with the ethical principles set in the Declaration of Helsinki for human experimentation and was approved by an institutional Research Review Committee. Subjects who were enrolled into the study gave informed consent after being informed about the aim of the study and the psychometric methods applied. No incentive was offered for enrolment into the study.

\section{Patients}

A total of 49 subjects undergoing psychiatric treatment and rehabilitation participated in the study; mean age $41.6 \pm 11.0(\mathrm{SD})$, range $23-59$ years, $\mathrm{F} / \mathrm{M}-18 / 31$. All subjects were diagnosed with paranoid schizophrenia (F20.0 according to ICD-10). The mean duration of the disease was $12.0 \pm 7.9$ years from the time of diagnosis. The inclusion criterion was that the patient be no less than 1 year from the beginning of an acute phase of the disease. The patients were in remission during the study, remaining on standard doses of the antipsychotic drugs risperidone and olanzapine. The exclusion criteria were an active schizoaffective disorder and pharmacological or otherwise antidepressive treatment. The educational status of the enrolled patients was as follows: 6 persons with primary education $(12.2 \%), 17$ with vocational education (34.7\%), 21 
with high school education $(42.9 \%$ ), and 5 with university education $(10.2 \%)$. With regard to the marital status, 30 persons were single $(61.2 \%), 9$ married $(18.4 \%), 7$ separated or divorced $(14.3 \%)$, and 3 patients were widowed $(6.1 \%)$. The study was conducted during January - May 2009.

\section{Psychometric TOOLS}

Each patient was given a set of questionnaires, joint together in this particular order: The Beck Depression Inventory (BDI-II), The Drwal Delta Inventory (DDI), The State-Trait Anxiety Inventory (STAI), The UWIST Mood Adjective Check List (UMACL), and The Coping Inventory for Stressful Situations (CISS).

The BDI-II is an instrument which assesses the intensity of depressive symptoms [11]. The score range is $0-63$, and a score of $\geq 12$ points was considered as suggestive of the presence of clinically significant depressive symptoms intensity. The DDI assesses the locus of control [12]. The questionnaire consists of 24 affirmative sentences requiring a "true or false" answer. Fourteen sentences pertain to one's conviction regarding the internal or external locus of control, and the remaining 10 assess the possible impact of a tendency to exaggerate oneself positive image; the latter questions are based on those found in the validity scales of personality inventories, in particular the EPQ-R lie scale. A high score in the DDI points to the external locus of control. The STAI consists of two subscales to assess the levels of state and trait anxieties [13]. The higher the score in a given scale, the higher is the anxiety level. For the assessment of mood, the UMACL was used [14]. This instrument consists of three subscales: tense arousal, energetic arousal, and hedonic tone. The UMACL includes 29 adjectives, with which one describes mood. The last instrument used in the study was the CISS which was created by Endler \& Parker [15]. The inventory con- sists of 48 items, which were assigned to the following subscales: task-oriented, emotion-oriented, and avoidance-oriented styles; the latter divided into the engaging in substitutional activities and the seeking of social interaction. The time for completion of the questionnaires was $35-45 \mathrm{~min}$.

\section{STATISTICAL EVALUATION}

Data are presented as means \pm SD of raw scores. Differences in the mean group scores between patients with and without depressive symptoms were compared with an unpaired t-test. Pearson's correlation coefficients were used to assess the relationships between depressive symptoms and psychological indices studied. A P value $<0.05$ was considered statistically significant.

\section{RESULTS}

There were $30(61 \%)$ schizophrenic patients who showed enhanced intensity of depressive symptoms, exceeding the 12 point cut-off mark in the BDI-II. The mean score for depressive symptoms in this group of patients was $23.3 \pm 8.7$ points, indicating mild-to-moderate intensity of depressive symptoms, which starkly contrasted the $5.7 \pm 3.3$ points in the non-depressive group of the remaining 19 subjects $(\mathrm{P}<0.05)$. There were no characteristic features which could distinguish depressive vs. non-depressive schizophrenic patients regarding the age, $42.1 \pm 10.6$ vs. 40.7 \pm 11.8 years, the gender, $\mathrm{F} / \mathrm{M}-11 / 19$ vs. $7 / 12$, and the disease duration $11.1 \pm 6.7$ vs. $13.5 \pm 9.5$ years, respectively. Nor were there major differences in the educational or marital status between the two groups.

However, a number of psychological indices, as presented in Table 1, differed appreciably between depressive and non-depressive patients. The locus of control was significantly more often placed externally

Table 1. Psychological indices in depressive and non-depressive schizophrenic patients.

\begin{tabular}{lccc}
\hline & Depressive & Non-depressive & $\mathbf{P}$ \\
\hline Depressive symptoms & $23.3 \pm 8.7$ & $5.7 \pm 3.3$ & 0.001 \\
External locus of control & $6.9 \pm 3.1$ & $4.7 \pm 2.8$ & 0.017 \\
& & & \\
Anxiety & $52.1 \pm 9.6$ & $35.3 \pm 7.5$ & 0.001 \\
$\quad$ State & $54.3 \pm 8.6$ & $39.3 \pm 7.9$ & 0.001 \\
$\quad$ Trait & & & \\
& & & \\
Mood & $23.2 \pm 4.1$ & $17.0 \pm 4.7$ & 0.001 \\
$\quad$ Tense arousal & $24.5 \pm 4.5$ & $30.1 \pm 4.2$ & 0.001 \\
$\quad$ Energetic arousal & $23.6 \pm 4.5$ & $32.6 \pm 4.1$ & 0.001 \\
$\quad$ Hedonic tone & & & \\
& & & \\
Coping with stress & $50.8 \pm 10.0$ & $59.2 \pm 10.3$ & 0.007 \\
$\quad$ Task-oriented & $47.5 \pm 7.6$ & $48.5 \pm 6.4$ & 0.646 \\
$\quad$ Avoidance-oriented & $23.6 \pm 4.3$ & $16.7 \pm 4.2$ & 0.317 \\
$\quad$ substitutional activities & $15.1 \pm 3.0$ & $39.4 \pm 9.2$ & 0.074 \\
$\quad$ social interaction & $50.3 \pm 7.4$ & 0.001 \\
$\quad$ Emotion-oriented & & \\
\hline
\end{tabular}

Values are means $\pm \mathrm{SD}$ of raw scores. 
in the depressive group; $6.9 \pm 3.1$ vs. $4.7 \pm 2.8$ points in the non-depressed ( $<<0.02$; DDI Questionnaire). The levels of both state and trait anxieties were remarkably higher in the depressive than in non-depressive schizophrenics; $52.1 \pm 9.6$ and $54.3 \pm 8.6$ vs. 35.3 \pm 7.5 and $39.3 \pm 7.9$ points, respectively $(\mathrm{P}<0.001$; STAI questionnaire). The depressive schizophrenics also displayed the appreciably enhanced levels of moody tense arousal and emotion-oriented strategies of coping with stressful situations; both having negative psychological connotations (UMACL and CISS questionnaires). By contrast, the positively connoted energetic arousal and hedonic tone as well as task-oriented coping with stress were decreased. All these data are summarized in Table 1.

Table 2 shows the results of analyses of the relationships between the intensity of depressive symptoms, as found in the BDI-II, and the psychological indices studied. Increasing intensity of depressive symptoms was positively related to the external locus of control, the anxiety traits, and tense arousal, whereas negative relations to depressive symptoms were attributed to energetic arousal and hedonic tone.

Table 2. Associations between the intensity of depressive symptoms and psychological indices assessed by Pearson's coefficients.

Correlation with depressive symptoms

\section{External locus of control}

$r=0.42, \quad P=0.002$

$\begin{array}{ll}\begin{array}{l}\text { Anxiety } \\ \text { State }\end{array} & \mathrm{r}=0.72, \quad \mathrm{P}=0.001 \\ \text { Trait anxiety } & \mathrm{r}=0.71, \quad \mathrm{P}=0.001 \\ \begin{array}{l}\text { Mood } \\ \text { Tense arousal }\end{array} & \mathrm{r}=0.63, \quad \mathrm{P}=0.001 \\ \text { Energetic arousal } & \mathrm{r}=-0.73, \quad \mathrm{P}=0.001 \\ \text { Hedonic tone } & \mathrm{r}=-0.64, \quad \mathrm{P}=0.001 \\ & \\ \text { Coping with stress } & \mathrm{r}=-0.29, \quad \mathrm{P}=0.043 \\ \text { Task-oriented } & \mathrm{r}=-0.13, \quad \mathrm{P}=0.387 \\ \text { Avoidance-oriented } & \mathrm{r}=0.10, \quad \mathrm{P}=0.509 \\ \quad \begin{array}{l}\text { substitutional activities } \\ \text { social interaction }\end{array} & \mathrm{r}=-0.32, \quad \mathrm{P}=0.027 \\ \text { Emotion-oriented } & \mathrm{r}=0.68, \quad \mathrm{P}=0.001\end{array}$

\section{Discussion}

The study demonstrates that the external placement of the locus of control, enhanced state and trait anxieties and tense arousal, and worsened mood are the cogent signs of depression in schizophrenic patients. Moreover, an increase in these indices may presage the intensification of depression. The study also demonstrates a substantial, over $60 \%$ incidence of depressive symptoms in schizophrenics. The latter finding is at variance with a report showing a 13\% incidence of depression among schizophrenics [16]. In that study, however, a 17 point cut-off level, higher than that in our study, was used in the BDI-II to define the presence of depressive symptoms. Aside from the percent- age differences concerning the prevalence of depression in schizophrenics, which are explicable by different populations and methodologies employed, there is a consensus that depression is a frequent and aggravating accompaniment of schizophrenia. Mulholland \& Cooper [3] have emphasized the fact that depression may be a prodromal symptom that precedes the acute phase of schizophrenia. Herz \& Melville [17] have reported that as many as $60 \%$ of patients and $75 \%$ of their family members pointed to depression as a factor preceding relapse. Depression may be present in both chronic and acute phases of the disease [18]. Depression interferes with the course of the disease, leading to exacerbations, and necessitates alterations in the treatment regimen $[4,10]$, let alone being the major cause of suicidal attempts. Mulholland \& Cooper [3] have reported that approximately $10 \%$ of schizophrenics die by suicide, and what is significant, most of them had had depressive episodes in their case histories or had exhibited signs of depression during contacts with the medical personnel.

Sands \& Harrow [19] have carried out a longitudinal study which was focused on describing differences between depression in schizophrenic patients and schizoaffective disorders. They also tackle the issues of whether some schizophrenics would be susceptible to depression and of the relationship between depression and social adjustment after discharge from the hospital in schizophrenia sufferers. The study included patients diagnosed with schizophrenia and depression, schizoaffective disorders of depressive type, psychoses combined with depression, and non-psychotic patients with depression. The authors show that $30 \%$ of schizophrenics had depressive symptoms at 4.5 years and $40 \%$ had such symptoms at 7.5 years into the disease. Depression in schizophrenia was associated with worse than that in the other conditions life adjustment after discharge, such as unemployment, low activity, general lack of satisfaction, suicidal tendencies, and a large number of subsequent re-hospitalizations. Furthermore, some schizophrenics were more susceptible to depressive symptoms than others many years after the acute phase of the illness, but neither the rate nor severity of depressive symptoms could distinguish depression in schizophrenia from schizo-depressive or major depressive disorders. In the present study, although we did not resolve the underlying mechanisms of the susceptibility to depression in schizophrenia, we believe we have shown that psychological assessment is capable of sorting out a subset of schizophrenic patients prone to the development of depression, allowing therefore for timely undertaking clinically significant countermeasures.

This study has limitations. A caution should be exercised in the interpretation of the BDI-II used in the present study to measure the intensity of depressive symptoms. Although this inventory has been shown to be well suited for the identification of depressive symptoms in stable, chronic schizophrenia [20] as well as other psychiatric patients [21], the results might not be replicable with other inventories of the kind. However, the nature of depressive symptoms in schizophrenic patients during remission is mainly associated with psychological factors, as opposed to the acute 
phase, in which the depressive symptoms are of the more classical biological type, which can be better detected, for instance, with the Hamilton Rating Scale for Depression. Consequently, one can assume that the BDI-II gave a reasonable insight into the occurrence of depressive symptoms in our patients. Furthermore, a relatively weak relationship between the external locus of control and depressive symptoms intensity may stem from the fact that the locus of control may be assumed a personality dimension. On this assumption, it would not be surprising that it would be less expressed in schizophrenia the axial symptom of which is personality degradation. Therefore, the results on the locus of control above outlined should be critically approached. The present study also was carried out in patients with the paranoid type of schizophrenia. The incidence of depressive symptoms and also their relation to the variables tested may not necessarily be applicable to other types of schizophrenia.

In conclusion, the external placement of the locus of control and the psychological indices typifying depression may be helpful in resolving doubts about the distinguishing between the negative and depressive symptoms of schizophrenia. As the presence of these indices likely antecedes the development of depression, we submit that psychological testing, possibly followed by behavioral therapy aimed at anxiety reduction, would help develop effective strategies to intervene with the disease process and thus should be part of health programs that address schizophrenia.

Acknowledgments: This study was supported by the Institute of Psychology of Opole University in Opole and by the Medical Research Center of the Polish Academy of Sciences in Warsaw, Poland.

Conflicts of interests: The authors declare no conflicts of interest in relation to this article.

\section{REFERENCES}

1. Pokorski M, Warzecha A. Depression and religiosity in older age. Eur J Med Res. 2011; 16: 1-6.

2. Barnes TR, Curson DA, Liddle PF, Patel M. The nature and prevalence of depression in chronic schizophrenic inpatients. Br J Psychiatry. 1989; 154: 486-91.

3. Mulholland C, Cooper S. The symptoms of depression in schizophrenia and its management. Adv Psychiatr Treat. 2000; 6: 169-77.

4. Siris SG, Bench C. Depression and schizophrenia. In: Hirsch SR, Weinberger DR (eds.), Schizophrenia. Blackwell Science: Oxford, 2003.

5. Caldwell CB, Gottesman II. Schizophrenics kill themselves too: A review of risk factors for suicide. Schizophr Bull. 1990; 16: 571-89.

6. Bartels SJ, Drake RE, McHugo GJ. Alcohol abuse, depression and suicidal behavior in schizophrenia. Am J Psychiatry. 1992; 149: 394-5.
7. Drake RE, Cotton PG. Depression, hopelessness and suicide in chronic schizophrenia. Br J Psychiatry. 1986; 148: 554-9.

8. Bandelow B, Muller P, Gaebel WE. Depressive syndromes in schizophrenic patients after discharge from hospital. Eur Arch Psychiatry Clin Neurosci. 1991; 240: 113-20.

9. Johnson D. Studies of depressive symptoms in schizophrenia. Br J Psychiatry. 1981; 151: 634-8.

10. Birchwood MJ, Jackson C. Schizophrenia. Psychology Press: Hove, East Essex, 2001.

11. Beck AT, Steer RA, Ball R, Ranieri W. Comparison of Beck Depression Inventories - IA and - II in psychiatric outpatients. J Pers Assess. 1996; 67: 588-97.

12. Drwal RL. Compiling a sense-of-control assessment delta questionnaire. Psychological Studies. 1979; 18: 67-84 (in Polish).

13. Spielberger CD. Manual for the state-trait anxiety inventory (STAI). Consulting Psychologists Press: Palo Alto, CA, 1983.

14. Matthews G, Jones DM, Chamberlain AG. Refining the measurement of mood: The UWIST mood adjective checklist. Br J Psychol. 1990; 81: 17-42.

15. Endler NS, Parker JDA. Multidimensional assessment of coping: A critical evaluation. J Pers Soc Psychol. 1990; 58: 844-54.

16. Baynes D, Mulholland C, Cooper SJ, Montgomery RC, MacFlynn G, Lynch G, Kelly C, King DJ. Depressive symptoms in stable chronic schizophrenia: Prevalence and relationship to psychopathology and treatment. Schizophr Res. 2000; 45: 47-56.

17. Herz M, Melville C. Relapse in schizophrenia. Am J Psychiatry. 1980; 137: 801-5.

18. Emsley RA, Oosthuizen PP, Joubert AF, Roberts MC, Stein DJ. Depressive and anxiety symptoms in patients with schizophrenia and schizophreniform disorder. J Clin Psychiatry. 1999; 60: 747-51.

19. Sands JR, Harrow M. Depression during the longitudinal course of schizophrenia. Schizophr Bull. 1999; 25: 15771.

20. Heald A, Morris J, Soni SM. Characterisation of depression in patients with schizophrenia. Indian J Med Res. 2008; 127: 544-50.

21. Borecki L, Gozdzik-Zelazny A, Pokorski M. Personality and perception of stigma in psychiatric patients with depressive disorders. Eur J Med Res. 2010; 15 Suppl II: 1016.

Received: May 14, 2011 / Accepted: July 8, 2011

Address for correspondence:

M. Pokorski

Medical Research Center

Polish Academy of Sciences

5, Pawinskiego St.

02-106 Warsaw, Poland

Phone/fax: +48 226086622

E-mail: m_pokorski@hotmail.com 